\title{
Women in ICT : Exploring Professional Identity on an Executive Masters Program
}

\author{
Sally Smith \\ School of Computing \\ Edinburgh Napier University \\ Edinburgh, UK \\ s.smith@napier.ac.uk
}

\author{
Colin Smith \\ School of Computing \\ Edinburgh Napier University \\ Edinburgh, UK \\ cf.smith@napier.ac.uk
}

\author{
Alison Varey \\ School of Computing \\ Edinburgh Napier University \\ Edinburgh, UK \\ a.varey@napier.ac.uk
}

\begin{abstract}
Despite years of purposeful activity there is still a shortfall in the numbers of women enrolling onto computing courses in the UK and elsewhere, while many who join the profession then leave. This 'leaky-pipeline' phenomenon is a concern for employers and reduces the pool of role models for the next generation of women. Finding out more about how women move into computing roles and how their careers progress may help us understand the role of computer science education in improving the talent pipeline of women. The purpose of this study was to explore the experience of a small group of women in computing and technology roles as they undertook an innovative work-based MSc in Strategic ICT Leadership with a view to gaining insights into how they view themselves as ICT professionals to add to existing work on gender and ICT. The Masters course is designed for experienced ICT professionals and covers key concepts such as ICT strategy, governance and ICT system delivery as a means to develop personal leadership. The award is of value in terms of skills development and also external recognition for the students. Adopting the lens of identity as a way of framing their experiences, the study explores how these women construct and adapt their professional identities as their professional roles change. To ascertain how effective the course was in meeting its aim to transform the ways students self-identify as professionals, the paper reviews the literature on professional identity in the ICT sector and considers two specific research questions; how do women in ICT roles construct their professional identities as they move into leadership roles, and what factors contribute to the adaptation of identity? Semistructured interviews deploying the life narrative approach uncovered insights into motivations and values held by women in leadership roles in ICT. Significantly, gender continues to impact the way professional women construct and redefine their identities as their careers develop. Professional identity was found to be closely aligned with organizational identity, with women showing clear commitment to organizational identities and allegiance to organizational mission and goals. The study also found that their leadership styles, in the absence of prototypical leaders, reflected their personal values. The importance of professional networks was highlighted and the course itself created new professional networks for the students. The study proposes that universities and employers
\end{abstract}

should consider, through course innovation, the transformational potential of Executive Masters courses as a means to support individual self-definition as ICT leaders.

Executive Masters; work-based learning; ICT professional identity; ICT leadership identity; identity adaptation; gender; computer science education

\section{INTRODUCTION}

The development of professional identify has been widely studied in established professions such as medicine and law, however Information \& Communications Technology (ICT) as a relatively new profession has been less widely explored through the lens of identity. This is problematic since ICT is a fast moving field with many and varied entry points, and computing professionals face particular challenges in keeping their skills up to date while migrating to new roles within their organizations, particularly leadership roles [1].

In response to some of the particular development challenges facing ICT professionals, a new and innovative work-based learning Executive Masters course, MSc Strategic ICT Leadership, was introduced at a UK university in September 2012. It was designed to provide a vehicle for professionals to develop their technology and leadership capabilities, and to support their transition into leadership roles in their organizations. The distinctiveness of the course emerges from the engagement with the professional students' own workplace responsibilities; assessments are designed to support the development of technology awareness, rigour and strategic thinking linked to workplace performance, leading to immediate and tangible benefits for them and for their organizations. The course has been very successful in attracting applicants at a stage in their career when they can benefit from this development opportunity, and many of the students have progressed significantly in their organizations (or secured promotions elsewhere) either during the course or soon after completion. In September 2013 the course was then adopted by a European project, Women Adding Value to the Economy (WAVE), as a strategic intervention in the Welsh labour market to bring about 
the up-skilling of women in ICT roles in Wales. Working with local partner, the Women's Workshop, two cohorts of professional women were recruited onto the course via WAVE.

The deployment of the MSc Strategic ICT Leadership presents a valuable opportunity to investigate the development of professional identity in this group of ICT professionals as they negotiate change and pursue opportunities in their professional lives. Through an examination of the literature on professional identity in ICT and leadership, a study was formulated drawing upon a life narrative technique designed to explore professional identity amongst women on the course. The need to better understand female perspectives on professional development in computing is pertinent due to the continuing under representation of women studying computing and entering the profession, coupled with the 'leaky pipeline' as careers progress. The purpose of this paper is, through an initial in-depth exploration of a small participant group, to better understand the experience of women in ICT leadership roles and in so doing to reconsider how universities should engage with potential female computing students and continue engagement throughout their working lives in order to reduce the number of women subsequently leaving the profession.

\section{GENDER and PROFESSIONAL IDENTICTY in ICT}

The gender imbalance in ICT remains a Western phenomenon with, for example, women making up just $16 \%$ of the workforce in the UK ICT sector [2]. In 2002 Cohoon made 19 recommendations for recruiting and retaining women in undergraduate computing majors which included: working with high school teachers, using role models in recruitment activity and reviewing all public information to eliminate unconscious bias [3]. Women have been found to choose computing because; it fits their strengths and capabilities; they find it creative; they receive encouragement from their friends and family and; in anticipation of a well-paid career [4]. Recruitment and retention of women in computing majors, certainly in the UK and the US, remains an ongoing project. More recently Frieze and Quesenberry [5] voiced concern that an essentialist approach was hampering progress, whereby finding the differences and targeting gender specific messages was, in fact, counter-productive. They point instead to a cultural change towards embracing diversity rather than attending to gender differences. What we do know, looking beyond university to the workplace, through studies on gender, work and identity in ICT, is that women have a greater affinity to users and less competitive approaches within their organizations $[6,7]$, favour business related and hybrid roles interpreting users requirements $[8,9]$, struggle with female geek imagery [10], make career decisions based on domestic arrangements [11] and experience a $16 \%$ gender pay gap [12]. Finally women are more likely than men to leave the profession. This 'leaky pipeline' phenomenon results in women being twice as likely to leave their jobs than men [13]. The reasons behind womens' decisions include a lack of recognition within their employer organizations and the search for a better work-life balance. Increasing participation of women in computer science education will only redress the gender imbalance in professional positions if some of the leaks can be plugged. This study aimed to explore how working life is experienced by women on the ICT leadership course through their self-identification within the ICT sector with a view to informing the debate on gender balance in ICT

Identity is considered by identity theorists to comprise the multiple roles people typically play together with the meanings attached to these roles [14]. Our roles as professionals underpin theories of professional identity and the way in which we identify as, for example, a skilled practitioner, educator, worker or manager. According to Ibarra [15], professional identity is 'the constellation of attributes, beliefs, values, motives, and experiences in terms of which people define themselves in a professional role': a perceived oneness with a profession [16]. Professional identity construction is considered to be the process by which a combination of technical skills, capabilities, status and roles merge with work and life experiences into a 'coherent image of self' [17]. Greater appreciation of how individuals self-identify can assist in understanding attachment, or feelings of belonging, to a profession. The construction of identity, using the definition above, is likely to be affected by both new skills and status, both of which can be acquired through the process of university education. Do universities then have a role to play in improving the attachment of women to the profession?

Professional identity studies in medicine, engineering and legal professions have uncovered how closely individuals identify themselves with their organisations or as members of a professional body (for example $[17,18,19]$ ). Brooks et al. [16] found that ICT professionals identify with the profession based on individual perceptions of the worth of ICT professionals as a group and perceived similarity to prototypical members of the profession. They also found that ICT professionals identify with the ICT profession based on 'need'. This need could be alignment to ICT in the face of organizational imperatives for ICT expertise or in the face of ongoing strategic ICT projects. Marks and Scholarios' study found a substantial degree of self-interest in a strong ICT professional identity, with ICT workers enjoying an external image of a 'highly regarded occupation' [20]. They also found that while the ICT profession is still considered highly specialised, some aspects of wider skills are now required including client facing and project management skills. Their research participants believed these to be part of their professional identity.

The Executive Masters course recruits students who are in-work and experienced ICT professionals with some line management responsibility. The course was designed to develop leadership capability using a strategic approach based on leading strategic change within the student's organization. DeRue and Ashford posit that the construction of a leadership identity requires three building blocks: individual self-perception, recognition of the role of leader through reciprocity in terms of the role of followers and, finally, endorsement through interactions within a shared context or situation [21]. What is not clear is the extent to which women in ICT self-identify as leaders, nor the level of endorsement they enjoy within their organizations. DeRue et al. [22] suggest that individuals are motivated to reinforce their self-concept by trying on leadership identities through claims made, for example, via narrative, behaviour and dress code. Dress and behaviour are ways of conforming to prototypical leader identities, however, with a shortage of women in ICT leadership roles it is not clear that prototypes or role models assist in identity construction to the same extent as in other professions. In a study of middle managers, Thomas and Linstead found managers changing the way they 
viewed themselves as a result of discourses of professionalism, gender, expertise, work ethic and performance [23]. These discourses acted as a resource providing self-verification and justification for their roles, for example, as 'breadwinners' considering a sacrifice in time spent with the family as consistent with managerial commitment. They also had 'feelings of fragility' about their roles as middle managers, compared with earlier skillsbased roles.

Lack of recognition has previously been cited as a reason for women leaving the profession [13]. As skilled ICT practitioners the students on the Executive Masters were at a stage in their careers of starting to engage with leadership development, with the award itself providing external recognition of capability. Studies of ICT leadership more frequently consider expectations of role holders than personal perspectives (for example, $[24,25,26]$ ). Previous studies have found that ICT managers felt they had to keep their skills sufficiently current to maintain credibility. However alongside this, they had to pick up business knowledge, interpersonal skills and political acumen to get things done within the company [27, 28]. Leadership styles such as Servant-Leaders, whereby the leader emerges through an initial desire to serve, with characteristics such as listening skills and empathy, are considered to offer much for modern organizations that are increasingly globalised, reliant on part-time and fixed term contracts, with some outsourced activity; all recognizable characteristics of the ICT sector [29].

Individuals hold multiple identities and professional identity is a non-essentialist identity whereby characteristics can change and the time and effort a person devotes to a role (or salience) can vary over time and in different situations [30]. The MSc in Strategic ICT Leadership recognizes change associated with study and was designed, in part, to increase the opportunity of ICT professionals to undertake identity work while embedded in their workplace. Identity work is the pre-cursor to identity adaptation and has been defined as the construction of identity through interactions with others to strengthen 'a sense of coherence or distinctiveness' [31].

The process by which professional identity is subsequently adapted has been linked to role models $[15,32,33]$, developmental networks [34] and experimenting with possible selves $[35,36,15]$. Each will be considered below.

Role models have been found to support identity construction and adaptation through emulation. According to Ibarra \& Petriglieri identity work involves compliance with role requirements and the external projections of professional identity, such as dress and behaviour [37]. In their study they observed identity work as individuals made transitions to new roles in order to 'convey images that conform to prototypic characteristics of those roles'.

Developmental networks consist of people and groups of people who take an active interest in an individual's career. They have been found to support self-verification in a professional role and in particular wide ranging networks have been found to have greater impact on professional identity than smaller more dense networks [38].

Finally, 'possible selves' is a term to describe imaginings of who one might become, in other words, a new self-identification. Trying on, or enacting, a new identity has been observed in studies that focus on role transitions and enactment is used until the new identity is consolidated (for example, [15]).

Based on the literature review, the following research questions emerged: (1) How do women in ICT roles construct their professional identities as they move in to leadership roles? (2) Where identity work is undertaken, what factors lead to an adaptation of identity? The study was designed to address these questions and, in so doing, consider the role of computer science educators in facilitating an improved gender balance.

\section{RESEARCH METHODOLOGY}

To explore the identity construction and adaptation of the women, a life narrative research method was used in the study. The life narrative is concerned with the lived experience; how individuals interpret their lives and their interactions with the world [39]. According to Fincher, "the central weakness of narrative as a singular representation is balanced by an intense qualitative richness' [40]. The questions posed in this study attempt to link the diverse events of role transition through an exploration of identity construction and adaptation.

Seventeen participants from the sample group of students on the MSc Strategic ICT Leadership course at a UK university and those studying in Wales agreed to take part in a study on professional identity. Six of the participants were women and this paper considers this sub-group. The students were full-time employees at senior levels of their organizations generally taking the course to upskill and gain a recognized Masters-level award either through personal motivation or the encouragement of their organizations. All students were responsible for leading strategic change within their organizations through the mechanism of the work-based learning component of the course which is a tripartite agreement between the student, the tutor and the line manager. The data was collected through audio recording and transcribing participants' life narratives by a single researcher. Life narratives in this context were used to enable data collection across a studying and working life, while not excluding the interactions between working and personal lives. Questions examined motivations for starting a career in ICT and reasons behind subsequent role changes; the process and experience of induction into roles; adjustments made when moving into new roles; training and development; interaction with networks and professional bodies; and finally, identification of recognisable role models. The data was coded through thematic analysis (for thematic analysis see, for example, [41]). The codes were categorised as:

- identity construction: organizational (IC1), skills-based (IC2) and leadership (IC3)

- identity work and adaptation: role models (IA1), developmental networks (IA2), possible selves (IA3) and selfdevelopment (IA4)

- personal identity: personal values (PI1) and work impacting home (PI2).

Validity of the narrative technique was checked through an initial pilot study to test the life narrative prompts on male and female participants. The six narratives formed part of a wider study which is yet to be completed, however the women's voices emerge from 
the initial analysis as distinctive and worthy of independent consideration. No claim for generalization can be made, however initial themes shedding light on routes for women into and through the ICT sector may be used to inform the computer science education sector and may prompt further studies.

\section{FINDINGS}

Two of the research participants (Anne and Belinda) could be described as pioneers in computing, having joined the profession early following self-recognition of an aptitude for technical problem solving. Both had had frequent role changes and experienced many technological advances over the course of their working lives. Both were employed as section heads, in health and housing organizations respectively, with sole responsibility for ICT within their sections. The remaining four participants (Claire, Lindsay, Margaret and Susan) effectively drifted in to computing through gaining systems skills within their main lines of work, increasingly moving into ICT roles and finding themselves with sole responsibility for ICT within their organizations. Each brought confidence and capability from a previous profession. Claire was leading a team of 15 in social care, Lindsay and Margaret were both responsible for ICT in small charities, Susan was leading a team of ICT business advisors. All participants were in roles where ICT directly affected end user working practices, where the end users were health professionals, non-ICT start-ups or vulnerable groups.

\section{A. Professional Identity Construction}

Unlike studies relating to other professions, none of the participants were members of a professional body, nor did they express any sense that this would have been valuable either to themselves or their organizations. Instead their professional identities could be viewed as having three components: organizational identity, technical skills-based identity and finally leadership identity.

In terms of an organizational identity (IC1), observed behaviour included sharing and valuing organizational goals, summed up by one participant: "I'm really loyal to what we do." While in general job satisfaction was expressed when discussing supporting the work of the organization, for all participants emphasis was placed on end users - and this was expressed in terms of providing a service. Anne expressed this as follows: "For me development isn't about a computer, development for me is about the outcome. Lots of people can do lots of things with a computer - if it doesn't benefit the service user what's the point?" and Claire: "We're very peoplecentred....it's all about outcomes for the service users." In terms of making a case for new technology, Belinda said "If the department has an objective, they need to achieve that and that's where the money is spent - which is probably the right way to do it to be fair." However there was also evidence that they did not believe the importance of ICT was fully recognized: "I think ICT as a whole needs to be accepted as something that is required for the business to survive."

There was more variation in terms of skills-based identity (IC2). For Anne, value was placed on her skills and she recognised the "struggle" she was experiencing now that members of the team she was leading had a higher level of skills related to one aspect of their project. Belinda admitted: "I love playing with the technical side. I don't get that much time to do it anymore and it is frustrating." Value was placed on quick fixes and problem solving, while external recognition of skills was also mentioned as a source of pride, Lindsay, describing a compliment from elsewhere in the organization, said: "I hadn't actually realized I'd made that much of an impact." Technical competence was a matter of both pride and satisfaction: "I really enjoyed taking something and making it work and again there's the satisfaction of helping others." Selfidentification as an expert was observed in the main by the two pioneers, Anne and Belinda. Both continue to search for new technology which could make a difference at work. However, some of the drifters downplayed their technical competence, for example, Claire: "I was self-taught... but it sort of came naturally to me" and Susan: "I've become s***-hot at Googling." There was however also some anxiety, for Margaret: "I suppose I struggled with the level of expertise I was getting involved in. I suppose that's where I had doubts" and Claire: "[My colleague and I] became experts which was a bit scary." Two participants relied on external help for technological changes and for Claire, handing over technical training to an external, when she had strong views about how it should be done: "I'm out of my comfort zone. I'm kind of struggling with it." Anne expressed concern: "I don't want to walk so far away from the ICT but I realise I have to move away a wee bit because I've not got the same technical skills now." The extent to which the skills based identity was salient depended both on job roles and previous experience.

Finally, leadership identity (IC3) although varied in terms of their organization's expectations, was expressed in a personal way with many describing coaching activity, acting as a mentor, supporting their staff to develop and empowerment of staff. Examples of leadership styles included, from Belinda: "I don't see a leader as stand-alone. I very much want input from other people" and Claire: "I don't do the big boss thing - it's not my gig." Two participants were emphatic in their view that leadership should not be disassociated from end users, Claire: "I've seen so many people [not going back to users] and forget why we're here" and Lindsay was relieved to leave a role which she felt had become too strategic and disconnected from users "I felt like I'd lost touch. I got so I just didn't want to get up in the morning."

All participants self-identified most strongly with their organizations. Beyond that the two pioneers self-verified as technical experts, and the four drifters identified as leaders. For all participants organizational identity was observed to be more salient than both technical skills-based and leadership identities.

\section{B. Identity Work and Adaptation}

The main identity adaptation themes from the literature (role models, developmental networks and possible selves) were observed however the impact of personal life on work identity was a new theme to emerge from the life narratives.

Role models (IA1) featured in four of the participants' narratives with impact ranging from helping make career decisions to presenting opportunities to observe and reflect on effective leadership behaviours. Anne was influenced by a team leader who knew the job inside and out: "If she thought she was right she would battle and I'm like that as well." 
Developmental networks (IA2) were mentioned by all six participants. For some, these networks were a chance to learn about other parts of their organization, for others these were small and dense networks of peers within a tight-knit group, for example, Susan: "we were a network of two but that worked well and we kept in touch and worked together again on a different project." The value placed on the networks was in the main social interactions or to seek reassurance rather than interactions that were specifically work related or related to technical knowledge transfer, for example: "Networking is useful, certainly when you're in a single post, for example, here when I was the only ICT person." However Claire had a different approach: "You have to start building relationships with people. I have to say there's been quite a few times when being the silly wee lassie did work, especially in a world of men." None of the participants related developmental networks with career advantage or as a means to gain status, however five from six had used their networks, developmental and social, to identify job opportunities.

The life narratives did not elicit any specific mention of possible or provisional selves (IA3), however implicitly Susan, when thinking about a new role, mimicked herself saying "I have a new job. I go to meetings now!" speaking in a way that was suggestive of a sense of satisfaction and pride, trying on her new identity ahead of the meetings in question. Belinda mentioned getting worked up ahead of important male dominated meetings, telling herself when she was anxious ahead of the event: "I have a good talk to myself. I just say, 'Yes you can. Just get on with it. Course you can'”, while Anne had identified a wider role that she thinks would be good for her organization and had rehearsed what she could bring to a new role: "I'm now the ICT specialist for that project....so if I can manoeuvre a post (laughs) this is my own wee personal agenda."

Table 2 captures the use of role models, developmental networks and possible selves, observed in the participants.

Table 2: Identity adaptation themes

\begin{tabular}{|l|l|}
\hline Identity adaptation theme & $\%$ observed \\
\hline Role models & $66 \%$ \\
\hline Developmental networks & $100 \%$ \\
\hline Possible selves & $50 \%$ \\
\hline
\end{tabular}

Training and self-development (IA4) offer an opportunity to undertake identity work. The skills gained from taking the Masters course were mentioned unprompted by all the participants and the course was highlighted also in terms of building confidence. Bringing learning from the course back to work to strengthen identity as an expert, Anne said: "Sometimes it's nice to know you're doing something right." Participants' motivations for attending the Masters course varied but in the main related to gaining confidence in their existing roles. Claire said taking the course was "not about self-advancement." Later in the narrative she said: "I know I said I didn't want a promotion but I'm not sure now I wouldn't move, whereas before the course I was like no way." Two of the participants had had to "struggle" with their organizations to attend. The self-development and self-reflection integrated into the course was observed to lead to identity consolidation and adaptation. Adaptation was largely facilitated by organizational, and wider, recognition of the Masters title combined with a new confidence in decision-making relating to ICT developments.

\section{Personal Identity}

The life narrative approach led to personal values (PI1) being observed, at the intersection of work and home. A consideration of the alignment of organizational values and personal values surfaced when choosing jobs. In one case of conflicting values, Belinda again: "I'd moved up a step, I'd increased my salary, but [the job] was awful. Within the first month I knew I would not be staying. My next job actually felt like going home." For Margaret, role choices had been influenced by "wanting to make a difference."

Five out of six selected roles because they fitted in with family life (PI2). The following is representative, from Belinda: "I took that big, big [career] step back. I made that conscious decision the kids are only young once." Some acknowledged that support from the family had made periods of overwork possible, Claire: "I was lucky and fortunate enough to have that home life environment where I didn't have to worry about my kids going to school, didn't have to worry about homework being done...My husband was just not career orientated so I was fortunate enough to have that."

\section{DISCUSSION}

The discussion section relates the findings to other studies and captures tentative recommendations for action designed to improve the gender imbalance in ICT. These suggestions are based on the participants' life narratives, recognising that these participants were investing further in their careers in ICT and remaining in the talent pipeline.

All participants were observed to have a strong organizational identity (IC1) in their current roles. Marks \& Scholaris also found salience in organizational identity in their study of ICT workers, noting that this was observed in particular where entry to the profession was not through a traditional computer science course [20]. The women were observed to self-identify less as technical experts than with their organizations, as expressed through loyalty to their organization's mission and project focus.

Recommendation 1: Employers wanting to attract and retain more women could reconsider their recruitment and retention messaging to prioritise the values of the organization over specific technical capabilities.

Skills-based identity (IC2) varied according to both individual expertise and the status of ICT within the organization. All participants, and the two pioneers in particular, were finding it difficult to prioritize management over technical activity. Identity conflict has been found elsewhere, for example by Alvesson [43] and Hotho [18], when group associations are challenged. The technical skills development on the Masters course was generally reported as used to confirm that what they were doing in the workplace was right - in effect consolidating their skills based identity. Likewise, Brooks et al. [16] found the need for ongoing technical skills development to enhance self-efficacy. Echoing Thomas and Linstead's study [23], four of the participants were anxious about losing their technical skills in the face of spending more time on management activity. 
Personal leadership identity styles (IC3) were observed together with a need for these to be authentic. With the lack of women in leadership roles, this could relate to the need to create new and personal leadership styles in the absence of prototypes of women ICT leaders (for prototypicality in leadership see [44]).

Role models (IA1) and developmental networks (IA2) were highlighted by all participants and this reflects findings and recommendations of previous studies (for example, [45]). Their observed interactions with role models and networks did not match the preconditions for identification as an ICT professional, as described by Brooks as a need to self-verify [16]. Instead neither role models nor members of developmental networks were identifiably prototypical members of the ICT profession. Unlike in previous studies which featured both men and women, none of these women used their networks as a means to enhance or even consolidate influence or status. They were used instead to support, reassure and to find out about job opportunities. Attending the Masters course itself was evidence of both effort and an attempt to increase capability, leading to identity adaptation, for example recognition within their organizations [21].

Personal values (PI1) and the salience of their identities as parents or daughters (PI2) were observed to influence career decisions and impact on job satisfaction. The participants had all found work that chimed with their personal values (PI1) and expressed satisfaction in helping end users. Kumpusalo et al. [42] found that medical professionals 'try to find workplaces that correspond as much as possible to their personal and professional identities' (p. 70) and this was observed in the participants in this study. The finding also echoes earlier work on motivations for women in ICT (for example, [8]). Indeed throughout their careers, participants had at times selected roles in organizations that corresponded to their personal and professional values and moved jobs when these were not aligned. In most cases these career decisions were not beneficial to status or income, however where personal values chimed with organizational values the impact on job satisfaction and motivation were positive.

Findings elsewhere suggest that the ICT sector has an image problem impacting on the profession's ability to attract and retain women. Stout \& Camp [46] make recommendations for interventions from school to employment so that 'everyone can benefit from recalibrating the computing community to be universally inviting, inclusive and engaging'. In early analysis of the life narratives of the male participants a divide appears to exist between the two groups. Only the women mentioned family as influencing decisions to reduce hours or move into lower status roles. While disappointing, this is hardly surprising. A poor work/life balance has been shown to be a factor in women leaving the profession [13]. In explicitly valuing the full range of skills and capabilities required to deliver organizational goals, while recognising preferences for personal values and promoting family friendly policies, the ICT sector might encourage more women in to the profession. Selection procedures themselves may introduce unconscious bias, for example, through imagery, advert copy and intensive coding competitions. Promoting more positive routes in to the sector, for example through developmental network referral, might support the cultural change that now looks necessary to shore up the leaky pipeline. In the meantime, women can start to speak to each other and encourage informal networks to develop.
Professional bodies, largely invisible to these women, may have a role to play alongside the ICT sector.

Recommendation 2: Employers should reconsider their expectations of work-life balance and promote appropriate policies when recruiting women into ICT at any stage.

Computing educators would also benefit from increased sector attractiveness. Four of the women in the study had drifted in to computing from other disciplines rather than seeking it out as a major to study. Finding the work interesting, challenging, creative and suiting their personal values led to the construction of organizational identity and narratives as problem solvers for the benefit of system users. So the challenge of attracting women in to study computing could hinge on a longer term view, through university and out into an industry that welcomes women. Universities' interactions with potential women applicants could be reviewed to better reflect women's working lives which in turn could encourage better gender balance on computing courses and subsequently in the ICT profession. Recognising lived experiences would benefit computer science educators considering course design and in so doing better prepare women for rewarding roles in ICT.

Recommendation 3: Educators and employer organisations should develop coherent messages for women highlighting the transformational nature of ICT.

Meanwhile the message of identity as a dynamic construct of organizational, technical and leadership identities emerging from the work in the study can be positive for both genders. This study found evidence of women engaging in satisfying careers and constructing and adapting identities which sat comfortably with their personal values and personal identities. Women were observed to be making conscious decisions to prioritise family and personal values ahead of money and status. These are the women who have remained in the pipeline. The study provides insights into their lives as professionals which can inform course design at both undergraduate and postgraduate levels.

Recommendation 5: Universities to consider designing courses for experienced ICT professionals which recognise the need to study while working and which can be used for external and internal recognition.

\section{CONCLUSION}

This study of professionals taking an innovative work-based learning Executive Masters, MSc Strategic ICT Leadership, found that the participants identified with their organizations through shared values. They were observed to be building careers based on positive professional and self-identity as problem solvers and caring leaders. In the context of a paucity of formal prototypical leaders, women moving into leadership roles in ICT were found to be committed to a strong organizational identity and a desire to retain their personal values including supporting users and prioritising home life. The emergent message here for universities and for the ICT sector to increase and retain the numbers of women opting for a career in computing is recognising attachment to the profession through the self-identification of women in ICT. 
Computer science educators will not be able to improve the gender balance alone; they need to work with employers to consider the entire proposition: from school through to first graduate jobs and beyond. An Executive Masters course combining leadership with skills development could form part of this proposition. The MSc Strategic ICT Leadership course offered the women in the study networking opportunities and a chance to consolidate a self enjoying recognition within their organization and externally. If we can encourage more women to remain in the talent pipeline they will be the role models for today's students.

\section{REFERENCES}

[1] C. DaSilva, P. Trkman, K. Desouza, \& J. Lindic, "Disruptive Technologies: A Business Model Perspective on Cloud Computing",Technology Analysis \& Strategic Management, 2013.

[2] Women in ICT Scorecard, 2014 http://policy.bcs.org/sites/policy.bcs.org/files/Women\%20in $\% 20 I C T \% 20$ scorecardv2.pdf

[3] J. Cohoon, "Recruiting and retaining women in undergraduate computing majors" ACM SIGCSE Bulletin, 34(2), 48-52, 2002.

[4] J. Cohoon, J. P. Cohoon, \& S. Turner, "Departmental factors in gendered attrition from undergraduate ICT majors", In Proceedings of NSF's ICTWF \& ICTR/EWF Principal Investigator Conference (pp. 23-25), 2006.

[5] C. Frieze \& J. Quesenberry, "From difference to diversity: including women in the changing face of computing", In Proceeding of the 44th ACM technical symposium on Computer science education (pp. 445-450). ACM, 2013.

[6] K. Sørensen, "Towards a feminized technology? Gendered values in the construction of technology", Social studies of Science, 22(1), 5-31, 1992.

[7] E. Gunnarsson, "Women and men-different rationalities?", Feminist Voices on Gender Technology and Ethics, 1994.

[8] M. Vehviläinen, "Gender in Information Systems Development-A Women Office Worker's Standpoint”, In Proceedings of the IFIP-Conference on Women, Work and Computerization in Helsinki. Amsterdam: North-Holland (pp. 247-262), 1991.

[9] Harvey Nash (2014) http://www.harveynash.com/womenintechnology/

[10] R. Bury, "She's geeky: The performance of identity among women working in ICT", International Journal of Gender, Science and Technology, 3(1), 2011.

[11] C. Castaño, \& J. Webster, "Understanding women's presence in ICT: the life course perspective", International Journal of Gender, Science and Technology, 3(2), 364-386, 2011.

[12] B. Runciman,"Ladies and Gents these are the Numbers", ICTNOW, 56(2), 60-61, 2014.

[13] T. Misa, (Ed.) "Gender codes: Why women are leaving computing”. John Wiley \& Sons, 2011.
[14] S. Stryker \& P. Burke, "The past, present, and future of an identity theory", Social Psychology Quarterly, 284-297, 2000.

[15] H. Ibarra, "Provisional selves: Experimenting with image and identity in professional adaptation", Administrative Science Quarterly, 44(4), 764-791, 1999.

[16] N. Brooks, C. Riemenschneider, B. Hardgrave \& A. O'LearyKelly, "ICT professional identity: needs, perceptions, and belonging" European Journal of Information Systems, 20(1), 87-102, 2010

[17] T. Cascio, J. Gasker, "Everyone has a Shining Side: Computer-Mediated Mentoring in Social Work Education", Journal of Social Work Education (Vol. 37, Issue 2), 284, 2001

[18] S. Hotho, "Professional identity-product of structure, product of choice: linking changing professional identity and changing professions", Journal of Organizational Change Management, 21(6), 721-742, 2008.

[19] H. Gunz, \& S. Gunz, "Hired professional to hired gun: An identity theory approach to understanding the ethical behaviour of professionals in non-professional organizations", Human Relations, 60(6), 851-887, 2007.

[20] A. Marks, \& D. Scholarios, "Revisiting technical workers: professional and organisational identities in the software industry”, New Technology, Work and Employment, 22(2), 98-117, 2007.

[21] D. DeRue \& S. Ashford, "Who will lead and who will follow? A social process of leadership identity construction in organizations", Academy of Management Review, 35(4), 627-647, 2010.

[22] D. DeRue, S. Ashford, \& N. Cotton, "Assuming the mantle: Unpacking the process by which individuals internalize a leader identity", Exploring positive identities and organizations: Building a theoretical and research foundation, 213-232, 2009.

[23] R. Thomas \& A. Linstead, "Losing the plot? Middle managers and identity”, Organization, 9(1), 71-93, 2002.

[24] G. Westerman, \& P. Weill, "What are the key capabilities of effective CIOs", Center for Information Systems Research, MICT, Cambridge, 2004.

[25] J. Rockart, "The changing role of the information systems executive: a critical success factors perspective", Massachusetts Institute of Technology, 1982.

[26] D. Green, “Knowledge management for a postmodern workforce: Rethinking leadership styles in the public sector", Journal of Strategic Leadership, 1(1), 16-24, 2008.

[27] G. Kunda, "Engineering culture: Control and commitment in a high-tech corporation", Temple University Press, 2009.

[28] Karahanna, E., \& Watson, R. T. (2006). Information systems leadership. Engineering Management, IEEE Transactions on, 53(2), 171-176.

[29] O. Guillaume, A. Honeycutt\& C. Cleveland, "Servant Leadership Trends Impact on 21st Century Business", International Journal of Business and Social Research, 2(5), $1-7,2012$ 
[30] K. Woodward, (Ed.), Identity and difference (Vol. 3). SAGE Publications Limited, 1997.

[31] S. Sveningsson \& M. Alvesson, "Managing managerial identities: Organizational fragmentation, discourse and identity struggle”, Human relations,56(10), 1163-1193, 2003.

[32] V. Singh, S. Vinnicombe, K. James, "Constructing a professional identity: how young female managers use role models", Women In Management Review, Vol. 21 Iss: 1 pp. $67-81,2006$.

[33] C. Wright., \& S. Wright, "The role of mentors in the career development of young professionals", Family Relations, 204208, 1987.

[34] V. Sweitzer, "Towards a theory of doctoral student professional identity development: A developmental networks approach", The Journal of Higher Education, 80(1), 1-33, 2009.

[35] H. Markus \& P. Nurius, "Possible selves", American psychologist, 41(9), 954, 1986.

[36] M. Ronfeldt \& P. Grossman, "Becoming a Professional: Experimenting with Possible Selves", Teacher Education Quarterly, 41-59, 2008.

[37] H. Ibarra \& J. Petriglieri, "Identity work and play", Journal of Organizational Change Management, 23(1), 10-25, 2010.

[38] S. Dobrow, \& M. Higgins, "Developmental networks and professional identity: A longitudinal study", Career Development International, 10(6/7), 567-583, 2005.

[39] G. Symon\& C. Cassell, "Qualitative methods and analysis in organizational research: A practical guide", Sage Publications Ltd 32, 1998.

[40] S. Fincher, "Using Narrative Methodology", University of Kent at Canterbury, 13, 2012.

[41] N. King, "Doing template analysis", Qualitative organizational research: Core methods and current challenges, 426-450, 2012.

[42] E. Kumpusalo, L. Neittaanmäki, K. Mattila, I. Virjo, M. Isokoski, S. Kujala, \& M. Jääskeläinen, "Professional identities of young physicians: A Finnish national survey", Medical Anthropology Quarterly, 8(1), 69-77. 1994.

[43] M. Alvesson, "Self-doubters, strugglers, storytellers, surfers and others: Images of self-identities in organization studies", Human Relations, 63(2), 193-217, 2010.

[44] M. Hogg, "A social identity theory of leadership", Personality and social psychology review, 5(3), 184-200, 2001.

[45] N. Dasgupta \& J. Stout, "Girls and Women in Science, Technology, Engineering, and Mathematics STEMing the Tide and Broadening Participation in STEM Careers", Policy Insights from the Behavioral and Brain Sciences, 1(1), 21-29, 2014.

[46] J. Stout \& T. Camp, "Now what?: action items from social science research to bridge the gender gap in computing research", ACM SIGCAS Computers and Society, 44(4), 5-8, 2014. 